\title{
Araştırma Makalesi https://doi.org/10.33484/sinopfbd.525579 \\ 1500 V DC Beslemeli Bir Metro Hattında Minimum Araç İşletme Geriliminin Performans Verilerine Bağlı Olarak Belirlenmesi
}

\author{
Mehmet Taciddin AKÇAY $Y^{a^{*}}$, İhan KOCAARSLAN ${ }^{b}$ \\ ${ }^{a}$ Ístanbul Büyükşehir Belediyesi, Raylı Sistem Daire Başkanlığı, İstanbul, Türkiye \\ ${ }^{b}$ TUVASAŞ, Sakarya, Türkiye
}

\begin{abstract}
$\ddot{O} \mathbf{z}$
DC beslemeli metro hatlarında elektrifikasyon sistemi tarafından sağlanan cer gücü besleme gerilimi vasıtasıyla aracın ihtiyacı olan güç sağlanmaktadır. Güç temini sağlanırken enerjinin kaliteli olması hedeflenir. Hat için sağlanan gerilimin belirli sınırlar dahilinde olması aracın performansını etkilemektedir. Hatta oluşan gerilim düşümüne bağlı olarak bu değer etkilenmektedir. $\mathrm{Bu}$ çalışmada $1500 \mathrm{~V}$ DC beslemeli bir metro hattında minimum araç geriliminin araç performans verilerine bağlı olarak belirlenmesi incelenmiştir. Çalışma için yapay zeka tekniklerinden olan Uyarlamalı Sinirsel Bulanık Çıkarım Sistemi (ANFIS) ve Destek Vektör Makinaları (SVM) yöntemleri tercih edilmiştir. Çalışma için SultangaziArnavutköy hattına ait bir grup performans verisi kullanılmıştır. Yapılan hesaplamalarla ideal sonuçlar elde edilmiştir.
\end{abstract}

Anahtar Kelimeler: ANFIS, cer, elektrifikasyon, metro, SVM.

\section{Determination of Minimum Vehicle Operating Voltage in a Metro Line with 1500 V DC Supply Based on Performance Data}

\begin{abstract}
In DC railways, the traction power supply voltage provided by the electrification system gives the power it needs. Energy is aimed to be of high quality while providing this power. The vehicle's performance is influenced when the voltage supplied for the vehicle performance is in certain limits. This value is affected by voltage drop on the line. In this study, the determination of the minimum vehicle voltage in a railway line with $1500 \mathrm{~V}$ DC supply in relation to the vehicle performance data was investigated. The artificial intelligence methods adaptive neuro-fuzzy inference system (ANFIS) and support vector machines (SVM) were applied. The performance data of Sultangazi-Arnavutkoy metro line were used in the study. Ideal results were obtained with the calculations.
\end{abstract}

Keywords: ANFIS, electrification, metro, SVM, traction.

\section{Giriş}

DC beslemeli demiryollarında birçok avantajından dolayı yaygın olarak $1500 \mathrm{~V}$ DC besleme gerilimi kullanılmaktadır. DC beslemeli demiryollarında enerji iletiminde katener kullanılırken geri dönüş iletkeni olarak raylar kullanılmaktadır. Katener pozitif kutbiyeti oluştururken raylar negatif

\footnotetext{
${ }^{*}$ Sorumlu Yazar: ORCID ID: orcid.org/ 0000-0002-1050-4566

e-mail: taciddin.akcay@ibb.gov.tr
}

Received: 11.02 .2019

Accepted: 23.07.2019 
kutbiyeti oluşturmaktadır. DC beslemeli raylı sistemlerde geri dönüş iletkeni olarak topraktan bağımsız bir iletken kullanıldığı için ray ile toprak arasında bir potansiyel farkı oluşmaktadır. Bu gerilimden dolayı ise raylardan toprağa doğru bir akım oluşmaktadır. Tasarımda ise ray ile toprak izole kabul edilmektedir [1-8]. DC beslemeli bir demiryoluna ait eşdeğer devre şekil 1'de gösterilmektedir.

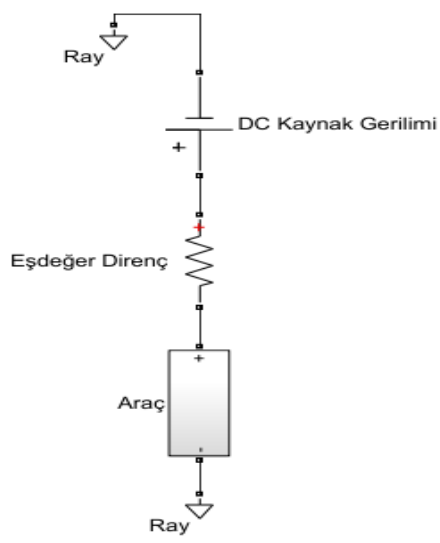

\section{Şekil 1: Eşdeğer Devre Modeli}

Devre en genel tanımla DC kaynak gerilimi, eşdeğer direnç, demiryolu aracı ve raylardan oluşmaktadır. Katener ve besleme kabloları ile diğer unsurlar eşdeğer dirence ilave edilmiştir. Denklem (1) ile aracın üzerindeki gerilim hesaplanmaktadır. Hatta oluşan gerilim düşümü eşdeğer dirençle doğru orantılıdır. Sistem topraktan izole olduğu için şematik olarak topraklama gösterilmemiştir.

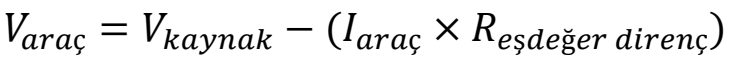
(1)

Burada $V_{\text {araç }}$ araç gerilimini, $V_{\text {kaynak }}$ besleme gerilimini, $I_{\text {araç }}$ aracın çektiği akımı, $R_{\text {eșdeğer direnç }}$ ise toplam direnci temsil etmektedir. Şekil 2 ile aracın hareketine ait durum gösterilmektedir. Araca etkiyen net kuvvet cer kuvveti ile harekete zit kuvvetlerin toplamının farkından oluşmaktadır. Aracın cer kuvveti hat geometrisine, aracın hızına ve işletme verilerine bağlı olarak değişmektedir. Araç yukarı doğru çıkarken eğim kuvveti araca zit kuvvet oluştururken, araç aşağı doğru indiğinde ise bu kuvvet aracın cer kuvvetiyle aynı yönde olmaktadır. Kurpların olduşturduğu kuvvet de ise kuvvetin yönü değişmemektedir [9-10].

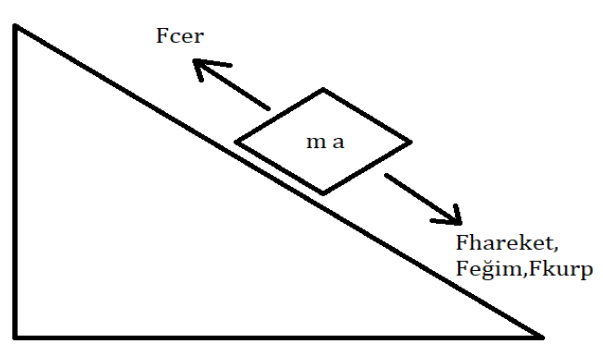

Şekil 2. Aracın Dinamiği

(2) nolu eşitlik ile aracın dinamik durumuna ait denklem verilmektedir. $\mathrm{Bu}$ eşitlikle aracın hareketi için gerekli cer kuvveti hesaplanmaktadır. 
$F_{c e r}=F_{\text {hareket }}+F_{\text {ĕgim }}+F_{\text {kurp }}+m a$

(2)

$F_{\text {cer }}$ cer kuvvetini, yani aracin hızlanması için gereken araç tarafından oluşturulan kuvvettir. $F_{\text {hareket hareket }}$ kuvveti aracın hareket direnç kuvvetini ifade etmekte olup aracin tasarımdan kaynaklanan ve çevresel etmenlerle oluşan dirençtir. $F_{\text {eğim }}$ eğim kuvvetini, $F_{\text {kurp }}$ kurp kuvvetini ifade etmektedir. Eğim kuvveti hatta bulunan eğim koşullarına bağlı olarak oluşan kuvveti, kurp kuvveti ise hattaki kurp değerlerine göre oluşan kuvveti göstermektedir. Eşitlikte $\mathrm{m}$ aracın dönel kütlesini a ise ivmeyi göstermektedir. Denklemde görüldügü üzere eğim ve dönel kurp sayısının artması ile aracın sağlaması gereken cer kuvvetinde artış meydana gelmektedir. Hareket direnci ise aracin tasarımına bağlı olarak değişmekte olup aracın hızına bağlı olarak değişmektedir. Aracın durduğu ve sabit hızla gittiği durumlarda ise araca etkiyen bu kuvvetlerin toplam değeri sıfır olmaktadır. Metro hatlarında aracın maksimum işletme hızı 80 $\mathrm{km} / \mathrm{sa}$ ya da $90 \mathrm{~km} / \mathrm{sa}$ olarak uygulanmaktadır. Bu çalışmada $1500 \mathrm{~V}$ DC beslemeli bir metro hattında minimum araç geriliminin araç performans verilerine bağlı olarak saptanması gerçekleştirilmiştir. Araç performans verileri olarak işletme sefer sıklığı, aracın çektiği güç, aracın çektiği limitli güç ve oran katsayısı kullanılmıştır. $\mathrm{Bu}$ verilerle aracın ihtiyacı olan minimum gerilim hesaplanmıştır.

\section{Bilimsel Yazın Taraması}

Literatürde DC beslemeli demiryolu elektrifikasyon sistemi ile ilgili çalışmalar olmasına rağmen performans verilerine bağl1 olarak minimum hat geriliminin incelendiği demiryolu elektrifikasyon sistemine ait bir çalışma bulunmamaktadır.

\section{Materyal ve Metot}

Yapay zeka tekniği ile insan düşünme yapısının benzeri bilgisayarlara aktarılabilir. Bunun için genelle ve geçmiş deneyimlerden öğrenme gibi yüksek zihin gücüne ilişkin görevleri elde edilen bir veri kümesi ile yapabilmektedir. Şekil 3'de yapay zekaya ait şekilsel gösterim verilmektedir.

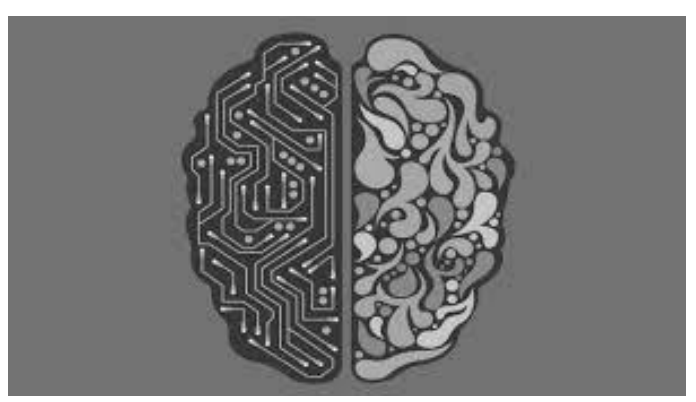

Şekil 3. Yapay Zeka Tekniği

$\mathrm{Bu}$ çalışmada yapay zeka tekniklerinden Uyarlamalı Sinirsel Bulanık Çıkarım Sistemi (ANFIS) ve Destek Vektör Makinaları (SVM) yöntemleri kullanılmıştır. Yapay zeka teknikleri 
yardımıyla araç minimum işletme geriliminin hesaplanması yapılmıştır.

ANFIS yapay sinir ağlarında bulunan eşgüdümlü hesaplama ve öğrenme yetenekleri ile bulanık mantıkta bulunan sonuç bulma yeteneklerinden yararlanan hibrit bir yöntemdir. SVM sinıflandırma konusunda kullanılan oldukça etkili ve basit yöntemlerden birisidir. Sınıflandırma için bir düzlemde bulunan iki grup arasında bir sınır çizilerek iki grubu ayırmak mümkündür. $\mathrm{Bu}$ sınırın çizileceği yer ise iki grubun da üyelerine en uzak olan yer olmalıdır. Benzetimler için Weka ve Matlab programları kullanılmıştır.

Uyarlamalı Sinirsel Bulanık Çıkarım Sistemiyle Tasarım (ANFIS)

ANFIS yöntemi Jang tarafindan geliştirilmiş olup doğrusal olmayan fonksiyonların modellenmesinde, kontrol sisteminde doğrusal olmayan bileşenlerin belirlenmesinde ve kaotik zaman serilerinin tahmininde kullanılmıştır [11-13]. $\mathrm{Bu}$ yöntem uyarlama özelliğine sahip ağların fonksiyon olarak bulanık sonuç alma sistemine benzer siniflarından biridir. Uyarlamalı Sinirsel Bulanık Çıkarım Sistemi kontrolörlerinin öğrenme tekniği, eşgüdümlü işleme, yapılandırılan bilgi davranışı gibi özellikleriyle farklı denetleme tasarım metotlarıyla daha iyileştirilmiş sonuçlar elde edilmektedir.
Sinir ağları ve bulanık mantık birbirlerinin eksiklerini tamamlayan yöntemlerdir. Yapay sinir ağları daha oluşumunu tamamlamamış verilerle çalışıldığında güzel neticeler elde eden bir yöntemdir. Bulanık mantık yapay sinir ağlarına göre daha profesyonel çalışma ile ortaya çıkarılan verilerden yararlanarak seviyesi daha yüksek neticeler elde etmektedir. Şekil 4'de ANFIS yapısı verilmektedir.

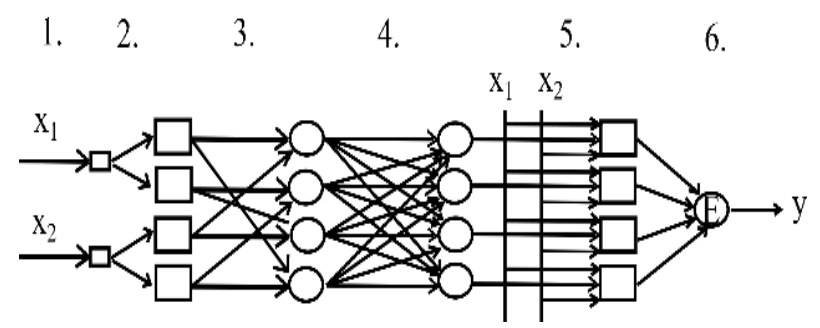

Şekil 4. ANFIS Yaplsı

Şekilde görüldüğü üzere ANFIS yapısı 5 adet katmandan oluşmaktadır. $\mathrm{Bu}$ çalışmada 4 girişli ve bir çıkışlı bir yapı oluşturulmuştur. Tasarlanan ANFIS yapısı şekil 5 ile gösterilmektedir.

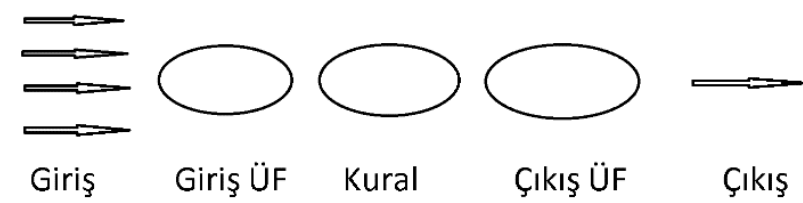

Şekil. 5. Tasarlanan ANFIS Yapısı

16 kurallı ANFIS yap1s1 tasarlanmıştır. Sistem giriş, giriş üyelik fonksiyonu, kural, çıkış üyelik fonksiyonu ve çıkış katmanlarından oluşmaktadır. 
ANFIS sisteminin tasarımı için $2^{4}$ $=16$ kural oluşturulmuştur. Benzetim için üçgen şekilli üyelik fonksiyonu kullanılmıştır. ANFIS sistemi için 4 girişli 2 üyelik fonksiyonlu bir mimari oluşturulmuştur.

\section{Destek Vektör Makinaları İle Tasarım (SVM)}

Destek vektör makinaları, eğitim verilerine ait bir noktaya en uzakta bulunan iki sınıf arasında bir karar sınırı bulan vektör uzayı tabanlı makine öğrenme metodu olarak tanımlanmaktadır. Bir destek vektör makinesini verileri optimum olacak şekilde iki gruba ayıran $\mathrm{n}$ boyutlu bir hiperdüzlem oluşturur. SVM modeli yapay sinir ağı yapılarıyla yakın bağlantılı olarak sigmoid bir kernel fonksiyonundan yararlanan SVM iki kısımlı, ileri beslemeli bir yapay sinir ağını kullanır. SVM'nin en önemli özelliği veri dizilerinde ortalama karesel hatanın minimizasyonu ile elde edilen ampirik risk minimum değerinin türetilmesinden ziyade, istatiksel olarak öğrenme kuramında bulunan yapısal risk değerinin minimum değerinin elde edilmesidir. Şekil 6 ile destek vektör makinasının yapısı verilmektedir. Destek vektör makinaları özellikle sınıflandırma problemlerinin çözümünde tercih edilmektedir [14-17].

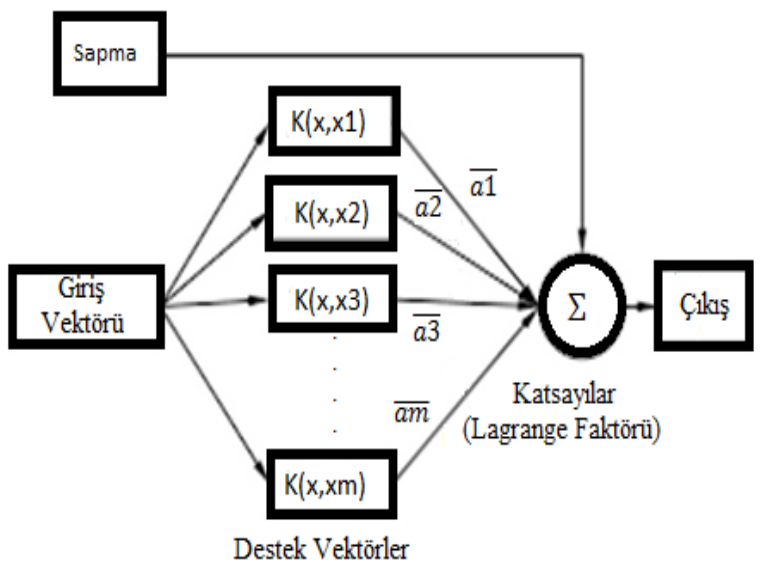

Şekil 6. Destek Vektör Makinaları Yapısı

4 girişli ve bir çıkışlı bir yapı tasarlanmıştır. Benzetimde en iyi sonucu almak için bir çok varyasyon denenerek ilgili SVM parametreleri seçilmiştir. Karmaşıklık parametresi olarak " $\mathrm{c}=1$ " seçilmiştir. Çekirdek fonksiyonu normalize edilmiş polinom çekirdek olarak seçilmiş olup üstel değeri olarak " $\mathrm{e}=3$ " alınmıştır. Hesaplamalarda 10-katl1-çapraz doğrulama yöntemi seçilmiştir.

\section{Sonuçlar}

Benzetim için 2000 adet veri dizisi kullanılmışştır. Kullanılan verilerden bir kısmına ait bilgiler tablo 1 ile verilmektedir. Sefer sıklığı, araca ait anlık toplam güç, aracın kullandığı güç, oransal değer ve minimum gerilim verileri araç performans kriterleri olarak kabul edilmiştir. 
Tablo 1. Kullantlan Veriler (1 Diziye Ait)

\begin{tabular}{lcc}
\hline Veriler & Giriş Değeri & Çıkış değeri \\
\hline Sefer Sıklığı(sn) & 90 & - \\
Anlık Toplam & & \\
Güç (kW) & 3554 & - \\
Kullanılan Güç & & \\
(kW) & 1516 & - \\
Oran & 0.43 & - \\
Minimum & & \\
Gerilim (V DC) & - & 1131 \\
\hline
\end{tabular}

\section{ANFIS Yöntemi ile Benzetim}

ANFIS tasarımına ait benzetim sonuçlarına ait regresyon grafiği şekil 7 ile verilmektedir. Gerçek değerlerle tahmin değerleri karşılaştırıldığında ideal sonuçlar elde edilmiştir.

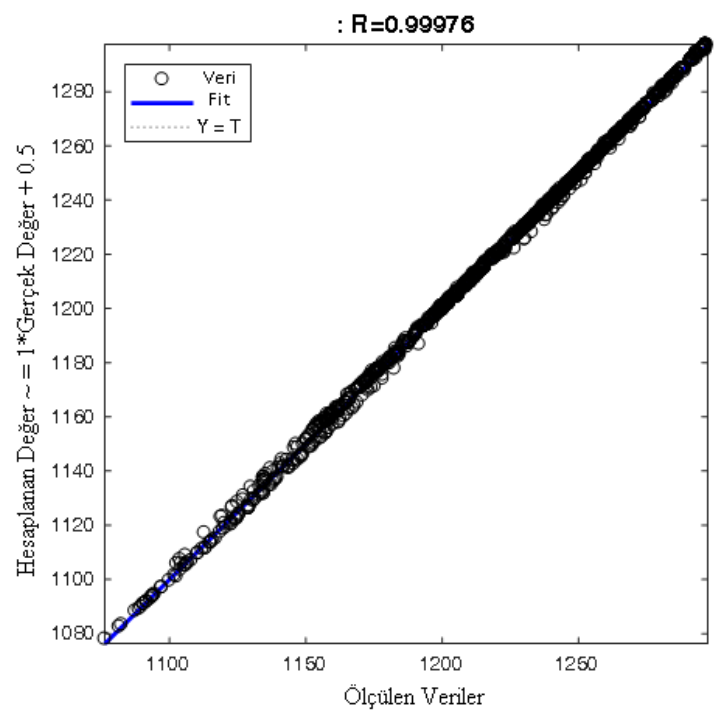

Şekil 7. ANFIS Regresyon Grafiği
ANFIS regresyon değeri 0.99976 olarak hesaplanmıştır. Sonuçların birleştirildiği eğri neredeyse 45 derece olmaktadır.

\section{SVM Yöntemi ile Benzetim}

SVM tasarımına ait benzetim sonuçlarına ait regresyon grafiği şekil 8'de gösterilmektedir. Gerçek değerlerle tahmin değerleri karşılaştırıldığında bu yöntem için de ideal sonuçlar elde edilmiştir. Bu durum sonuçların olumlu olduğunu göstermektedir.

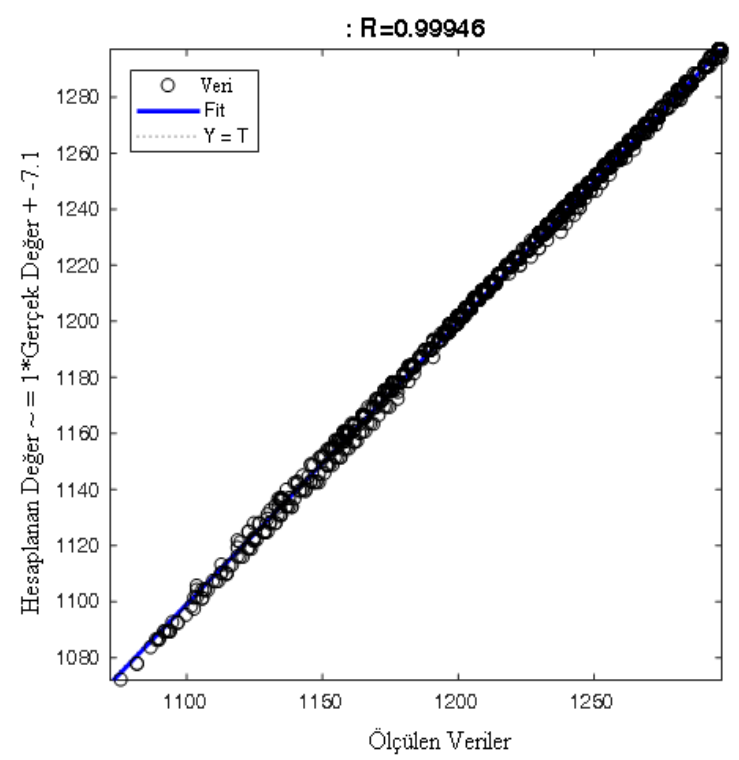

Şekil 8. SVM Regresyon Grafiği

SVM regresyon değeri 0.99946 olarak hesaplanmıştır. Sonuçların birleştirildiği eğri bu yöntem için de neredeyse 45 derece olmaktadır. 
İki Yönteme Ait Sonuçların

\section{Karşılaştırılması}

İki yöntem karşılaştırıldığı zaman Tablo 2 ile verilen özet tablo elde edilmektedir. Tabloda görüldüğü üzere ANFIS yöntemine ait sonuçlar SVM yöntemiyle elde edilen sonuçlara göre daha iyi olmaktadir.

Tablo 2. İki Yönteme Ait Sonuçlar

\begin{tabular}{lcc}
\hline Metot & ANFIS & SVM \\
\hline $\begin{array}{l}\text { Ortalama Mutlak Hata } \\
\text { (MAE) }\end{array}$ & 0.5879 & 1.0662 \\
Karesel Ortalama Hata & & \\
(RMSE) & 0.9506 & 1.4762 \\
Göreceli Mutlak Hata & & \\
(RAE) & 0.0200 & 0.3094 \\
$\begin{array}{l}\text { Göreceli Kök Karesel } \\
\text { Hata(RRSE) }\end{array}$ & 0.2460 & 0.3390 \\
Örnekleme Sayıs & 2000 & 2000 \\
\hline
\end{tabular}

ANFIS ve SVM yöntemi olmak üzere iki Yöntem için de ideal sonuçlar elde edilmiş olup tahmin edilen değerler gerçek değerler yerine kullanılabilir.

\section{Tartışma}

Bu çalışmada yapay zeka teknikleri kullanılarak DC beslemeli demiryollarında minimum hat gerilimi araç performans verilerine bağlı olarak hesaplanmıştır. DC beslemeli demiryollarında işletme sürekliliği için aracın minimum gerilimi belirli limitler içerisinde kalmalıdır. $\mathrm{Bu}$ çalışma ile yapay zeka tekniklerinden ANFIS ve SVM yöntemleri kullanılarak yapılan benzetim çalışmaları ile ideal sonuçlar elde edilmiştir. Çalışma için 2000 adet veri dizisi kullanılarak çalışmanın doğruluğu arttırılmıștır. Çalıșma sonucunda tablo 2'de görüldüğü gibi ideal sonuçlar elde edilerek minimum araç gerilimi bulunmuştur. ANFIS ile elde edilen sonuçların SVM yöntemiyle elde edilen sonuçlara göre daha iyi olduğu anlaşılmıştır. Elde edilen performans hesaplarıyla ANFIS MAE değeri 0.59 iken SVM için bu değer 1.07 olmaktadır. RMSE değeri ise ANFIS için 0.95 olurken SVM için 1.48 olmaktadır. ANFIS RAE değeri 0.02 iken SVM'de 0.31 olmaktadır. ANFIS için 0.25 olan RRSE değeri SVM için 0.34 değerini almaktadır. Tüm bu sonuçlar değerlendirildiğinde elde edilen tahmin hesaplamalarının ideal ve kullanılabilir olduğu görülmektedir. Bu çalışma ile araç performans kriterlerinin değişmesine bağlı olarak sisteme dinamik bir işletme yapısı kazandirılmaktadır.

\section{Kaynaklar}

[1] Ibrahem, A., Elrayyah, A., Sozer, Y., Garcia, J., A., A., 2017. DC Railway System Emulator for Stray Current and Touch Voltage Prediction. IEEE 
Transactions on Industry Applications, 53: 439-446.

[2] Meghwani, A., Chakrabarti, S., Srivastava, S., C., 2016. A Fast Scheme for Fault Detection in DC Microgrid Based on Voltage Prediction. National Power Systems Conference (NPSC), Bhubaneswar, India.

[3] Lao, K., W., Wong, M., C., Dai, N., Y., Wong, C., K., Lam, C., S., 2016. Analysis of DC-Link Operation Voltage of a Hybrid Railway Power Quality Conditioner and Its PQ Compensation Capability in HighSpeed Cophase Traction Power Supply. IEEE Transactions On Power Electronics, 31: 1643-1656.

[4] Ghassemi A, Fazel SS, Maghsoud I, Farshad S., 2014. Comprehensive study on the power rating of a railway power conditioner using thyristor switched capacitor. IET Electrical Systems in Transportation, 4: 97-106.

[5] Raimondo G, Ladoux P, Lowinsky A, Caron H, Marino P., 2012. Reactive power compensation in railways based on $\mathrm{AC}$ boost choppers. IET Electrical Systems in Transportation, 2: 169-177.

[6] Aodsup K, Kulworawanichpong T., 2012. Effect of train headway on voltage collapses in high-speed AC railways. In: APPEEC 2012. Power and Energy Engineering Conference; 27-29 March, Shanghai, China, New York, USA, IEEE: $1-4$.

[7] Abrahamsson L, Kjellqvist T, Ostlund S., 2012. High-voltage DC-feeder solution for electric railways. IET Power Electronics, 5: 1776 - 1784.
[8] Goodman CJ, Chymera M., 2013. Modelling and simulation. In: REIS Railway Electrification Infrastructure and Systems Conference; 3-6 June, London, England. New York, USA: IEEE: 16-25.

[9] Ladoux P, Raimondo G, Caron H, Marino P., 2013. Chopper-Controlled steinmetz circuit for voltage balancing in railway substations. IEEE Transactions on Power Electronics, 28: 5813-5822.

[10] Shin HS, Cho SM, Huh JS, Kim, JC, Kweon, DJ., 2012. Application on of SFCL in automatic power changeover switch system of electric railways. IEEE Transactions on Applied Superconductivity, 22: 560-704.

[11] Ozkan IA, Saritas I, Herdem S., 2007. Modeling of magnetic filtering with ANFIS. In: 12. National Conference on Electrical Electronic Computer Biomedical Engineering; 14-18 November, Eskisehir, Turkey. Ankara, Turkey: CEE: 415-418.

[12] Sit S, Ozcalik HR, Kilic E, Dogmus O, Altun M., 2016. Investigation of performance based on online adaptive neuro-fuzzy inference system (ANFIS) for speed control of induction motors. Cukurova University Journal of the Faculty of Engineering and Architecture, 31: 33-42.

[13] Jang, JSR., 1993. ANFIS: Adaptivenetwork-based fuzzy inference system. IEEE Transactions on Systems, Man, and Cybernetics ,23: 665-685.

[14] Ayhan, S., Erdogmus, S., 2014. Kernel function selection for the solution of classification problems via support vector machines, Eskisehir Osmangazi University Journal Of IIBF, 9: 175-198. 
[15] Yakut, E., Elmas, B., Yavuz, S., 2014. Predictıng stock-exchange index using methods of neural networks and support vector machines, Suleyman Demirel University The Journal Of Faculty Of Economics And Administrative Sciences, 19: 139-157.

[16] Kavzaoglu, T., Colkesen, I., 2010. Investigation of the effects of kernel functions in satellite image classification using support vector machines, Gebze High Technology Institute The Journal of Map, 144: 73-82.

[17] Guran, A., Uysal, M., Dogrusoz, O., 2014. Effects of support vector machines parameter optimization on sentiment analysis, DEU Engineering Faculty The Journal Of Engineering Sciences, 16: 8693. 